\title{
Vila Flores: Um Processo Arquitetônico
}

\section{Vila Flores: Un Proceso Arquitectónico}

\section{Vila Flores: An Architectural Process}

DOI: 10.17981/mod.arq.cuc.22.1.2019.02

Artículo. Fecha de Recepción: 02/15/2019. Fecha de Aceptación: 03/30/2019.

\section{Roberta Edelweiss}

Universidade do Vale do Rio dos Sinos (UNISINOS)

robertaedelweiss@gmail.com

Para citar este artículo:

Edelweiss. R. (2019). Vila Flores: Um Processo Arquitetônico, MODULO ARQUITECTURA CUC, vol. 22, no. 1, pp. 49-68, 2019. DOI: http://doi.org/10.17981/mod.arq. cuc.22.1.2019.02

\section{Resumo}

O artigo apresenta uma discussão sobre o processo arquitetônico do Vila Flores, em Porto Alegre. A partir do entendimento dos paradigmas advindos da contemporaneidade, o artigo, além de descrever as transformações do Vila Flores ao longo da história, identifica no mesmo conceitos de código aberto, de operação de baixo para cima e de organização sistêmica. Em conclusão, o artigo entende o Vila Flores como um exemplo de processo arquitetônico pautado pelas questões impostas pela contemporaneidade.

Palavras-chave: Contemporaneidade; Processo arquitetônico; Vila Flores

\section{Resumen}

El artículo presenta una discusión sobre el proceso arquitectónico del Vila Flores, en Porto Alegre. A partir del entendimiento de los paradigmas que vienen de la contemporaneidad, el artículo, además de describir las transformaciones de Vila Flores a lo largo de la historia, identifica en el mismo concepto de código abierto, de operación de abajo hacia arriba y de organización sistémica. En conclusión, el artículo entiende el Vila Flores como un ejemplo de proceso arquitectónico pautado por las cuestiones impuestas por la contemporaneidad.

Palabras-clave: Contemporaneidad; Proceso arquitectónico; Vila Flores

\section{Abstract}

The article presents a discussion about the architectural process of Vila Flores, in Porto Alegre. From the understanding of the paradigms arising from contemporaneity, the article, besides describing the transformations of Vila Flores throughout history, identifies in the same concepts of open source, low-up operation and systemic organization. In conclusion, the article understands Vila Flores as an example of an architectural process based on the issues imposed by contemporaneity.

Keywords: Contemporaneity; Architectural process; Vila Flores 


\section{INTRODUÇÃO}

A mostra brasileira para a $15^{\mathrm{a}}$ Bienal de Internacional de Arquitetura Veneza de 2016, de nome "Juntos" e de curadoria de Washington Fajardo, apresenta-se como resposta à proposição de Alejandro Aravena, diretor da $15^{a}$ edição da Bienal - Reporting from the front. A mostra apresentou 15 projetos brasileiros de diferentes regiões e atuações com pontos em comum a respeito de métodos participativos e processos inclusivos. De acordo com o curador da mostra Washington Fajardo "a mostra é uma composição dessas trajetórias e parcerias, do processo do encontro do ativista, do lutador, com o arquiteto e com a arquitetura, tornando-se irmanados pela elaboração do novo espaço". (Fundação Bienal de São Paulo, 2018). Os projetos expostos trazem uma questão até então pouco explorada nos debates do mundo arquitetônico: a arquitetura como ferramenta social em conquista de processos de bottom-up architecture (arquitetura de baixo para cima).

O projeto do Vila Flores, de 2012, por sua vez, foi um dos projetos selecionados e apresentados na mostra em questão. O Vila Flores trata de um projeto não convencional, realizado em etapas e aberto à participação da comunidade. Segundo um dos autores do projeto, o arquiteto e urbanista João Felipe Wallig e Vitor Pena, o Vila Flores trata-se de
... um núcleo de resistência originado em um bem privado, que hoje presta serviços de utilidade pública através de ações que fomentam a preservação do patrimônio material e imaterial, o acesso à cultura, o desenvolvimento de novas tecnologias sociais, valorizando a arte em todas as suas linguagens e o crescimento do empreendedorismo criativo" (Walling e Pena, 2016).

Para os autores do projeto do Vila Flores - o escritório de arquitetura e urbanismo Goma Arquitetura e a Associação Cultural Vila Flores - o mesmo recebeu o adjetivo de "processo arquitetônico: ressignificação, coletividade e aprendizado na recuperação de patrimônio histórico e cultural de Porto Alegre". É a partir da conceituação de processo arquitetônico, portanto, que o presente artigo, disserta sobre o processo do Vila Flores e as questões contemporâneas referentes à sua criação.

\section{Vila Flores: Um Processo Arquitetônico}

O Vila Flores é uma associação sem fins lucrativos, existente desde 2013, e formalizada em 2014. Trata-se de um espaço de trabalho de dezenas de artistas e empreendedores criativos. O conjunto de edificações situa-se na antiga região industrial na várzea do Rio Guaíba, Porto Alegre, pertencente ao bairro Floresta. As edificações estão listadas no Inventário do Patrimônio Cultural de Bens Imóveis do Bairro Floresta, classificadas como imóveis de Estruturação e situadas em Área de Interesse Cultural de Porto Alegre. 
1. If FIS 
Após o descaso ocorrido com a região, atualmente novos olhares se voltam para o $4^{\circ}$ distrito, vendo uma oportunidade da criação de um pólo criativo e cultural. A região tem como pontos positivos a proximidade com o centro, o uso misto, o preço acessível do aluguel, e também se encontra próximo a entrada e saída de Porto Alegre. Sendo assim, as novas iniciativas para a região do $4^{\circ}$ distrito se caracterizam por um ideal coletivo. Galpões de velhas fábricas são adaptados em ambientes capazes de reunir diferentes empresas em um mesmo espaço, que compartilham o ambiente e equipamentos. Além disso, a promoção de eventos por meio de parcerias entre empreendedores passou a atrair pessoas para atividades de lazer.

O conjunto foi construído entre os anos 1925 e 1928, o primeiro prédio foi projetado e construído pelo engenheiro-arquiteto José Franz Seraph Lutzenberger, e o segundo com a parceria do engenheiro junto com a multinacional Dyckerhoff \& Widmann s.a. 0 arquiteto nascido na Alemanha em 1882, veio para Porto Alegre em 1920, devido o fim da Primeira Guerra Mundial.Em 1922 projetou seu primeiro projeto individual na cidade: a obra da Igreja São José. Posteriormente o Orfanato Santo Antônio do Pão dos Pobres (1925), o Sanatório Leprosário Rio-Grandense (1929), o Colégio Nossa Senhora das Dores (1926-36), e em 1937 o Palácio do Comércio. Suas obras caracterizavam-se principalmente pela funcionalidade, com soluções formais, empregando um estilo eclético com tendência ao déco, e eliminando ornamentações supérfluas.

O escritório Goma Oficina, em artigo para Archdaily (2016) descreve que

o conjunto é formado por dois prédios de três andares, todos eles construídos com sobreposição de estrutura (alvenaria portante e concreto armado) e um galpão de alvenaria, conformado juntos o pátio interno. São $2.332 \mathrm{~m} 2$ construídos em um terreno de $1.415 \mathrm{~m} 2 \mathrm{O}$ conjunto conta com poucos adornos e bay-windows nas suas salas principais. No projeto original, Lutzenberger garantiu uma excelente implantação aproveitando-se da iluminação natural e ventilação cruzada, além de boa distribuição entre área construída e vazios abertos.

Devido à diversificação dos tamanhos das unidades destinadas ao uso misto - serviços e loja no térreo, apartamentos de um, dois e três quartos no segundo e terceiro pavimento - e pela concepção dos espaços de uso comum estarem presentes no projeto original de Joseph Lutzenberger, nota-se que a ideia da criação de um espaço compartilhado já estava sendo pensada pelo arquiteto. O prédio (Figura 3) foi construído para servir como moradia de aluguel para os funcionários da região industrial e, até 2010, não teve seu uso modificado, o que garantiu a preservação das suas características tipológicas. 


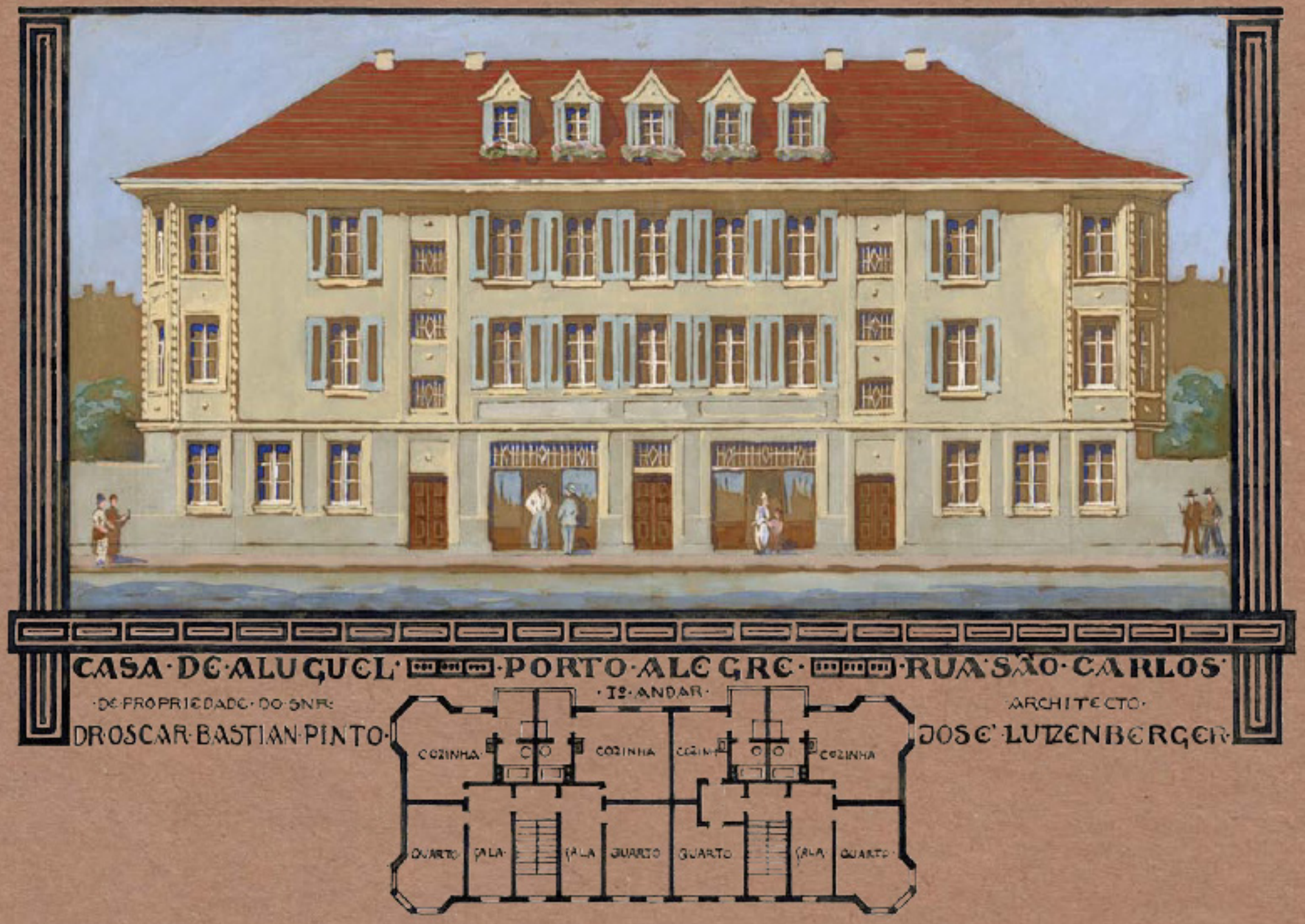

Figura 3. Aquarela feita pelo arquiteto Joseph Lutzenberger. Fonte: Arquivo João Felipe Wallig. 
O local foi herdado por dois irmãos (um arquiteto e uma pedagoga) em 2010. Ambos viram, na economia criativa, uma nova proposta de ocupação da Vila Flores. A iniciativa visa a revitalizar o conjunto e ativá-lo como um espaço cultural, núcleo de práticas colaborativas, capaz de contribuir para a renovação cultural do $4^{\circ}$ distrito da cidade. Wallig e Sielski (2013) relatam que a nova geração de proprietários está promovendo a reabilitação do conjunto e prevê -junto a comunidade do local, artistas e coletivos da cidade -, a readequação do seu uso em prol das práticas colaborativas relacionadas à economia criativa, no intuito de contribuir para a revitalização cultural do $4^{\circ}$ Distrito.

Em meio a essas iniciativas, a comunidade local se sensibilizou e passou discutir a respeito das possibilidades de melhorias para região. Sendo criado então o Refloresta - Associação de Moradores do Bairro Floresta -, deu-se início a diversas atividades, como a criação de um brechó comunitário. Assim,

a apropriação dos espaços de convívio foi de alguma forma se ampliando ou pelo menos sendo reivindicada e neste conjunto de ações o Projeto Vila Flores tornou-se mais uma possibilidade de alavancar práticas artísticas colaborativas em diálogo com a cidade, o bairro e a comunidade (Wallig e Sielski, 2013, p. 2).

Em 2011, com o cuidado de não descaracterizar o projeto original de José Lutzenberger, deu- -se início ao estudo do projeto da recuperação e reforma das edificações. Segundo João Felipe Wallig (2018) "A diretriz de projeto foi manter a volumetria dos elementos históricos e intervir de maneira pontual, como a estrutura a questão dos usos e da acessibilidade". O projeto inicial tinha a intenção de transformar o espaço em galeria, restaurante, café, salas de exposições, habitação temporária e salas comerciais. A família logrou investir e realizar as reformas emergenciais de estruturas básicas. Em seguida, a implementação do projeto Vila Flores, envolveu a comunidade e evidenciou a vontade de preservação e construção de um espaço coletivo.

Neste cenário dialógico - de discussão com a comunidade para análise de possíveis cenários para as edificações - observam-se práticas insurgentes de colaboração que estão diretamente relacionadas à lógica de redes. A superação do modelo de produção baseado em consumo e excesso de produção apresenta-se como um novo cenário. A contemporaneidade, neste sentido, apresenta-se como um campo aberto de investigação. Assim, a contextualização do estudo de caso do Vila Flores é de suma relevância para o presente trabalho. Essa contextualização, bem como a conceituação de questões insurgentes do contemporâneo - como o código aberto - o modo de operação de baixo para cima, e a organização sistêmica são elementos que justificam o processo arquitetônico. 
Figura 4. Situação que o bem patrimonial se

encontrava antes das reformas emergenciais. Fonte: Arquivo João Felipe Wallig.

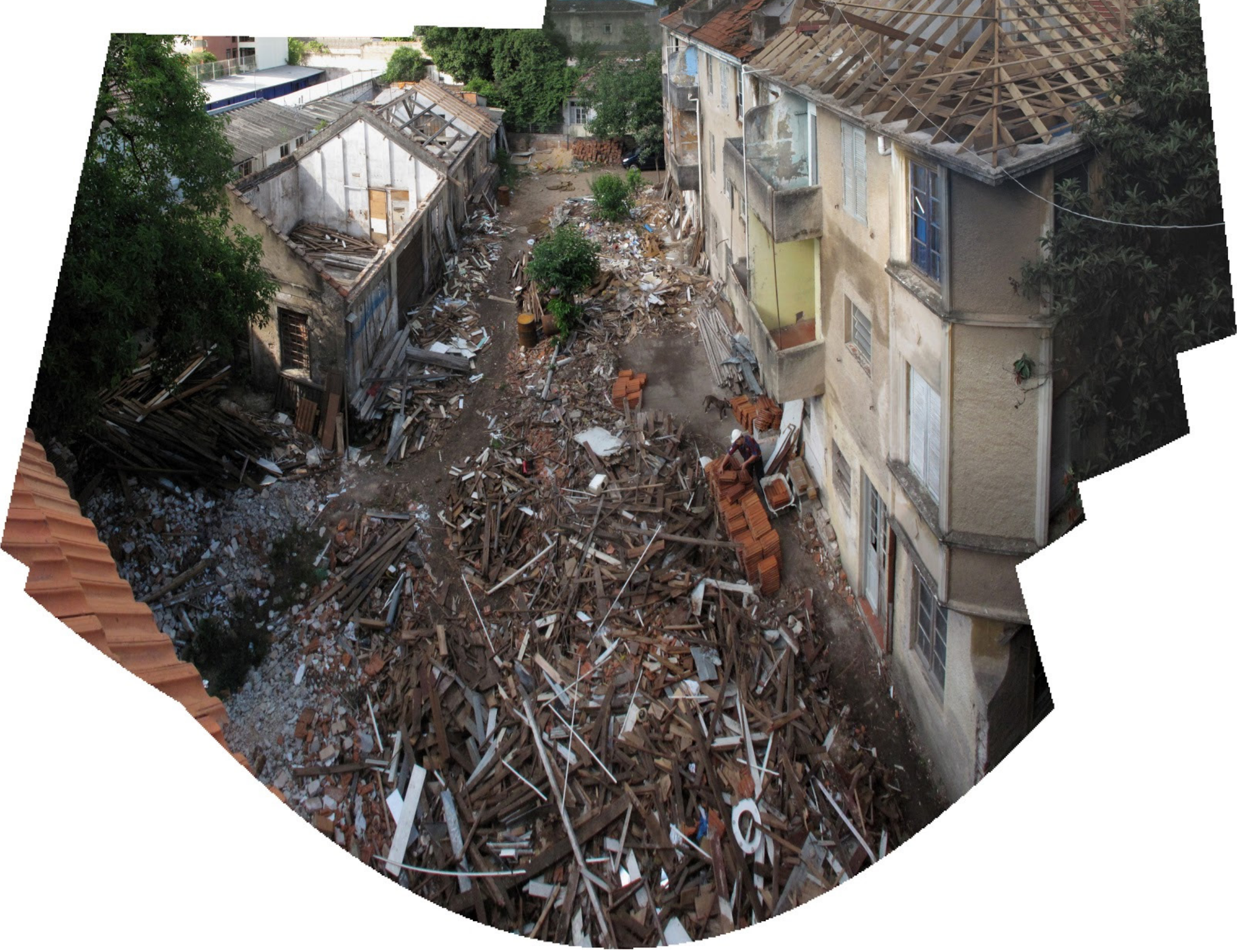




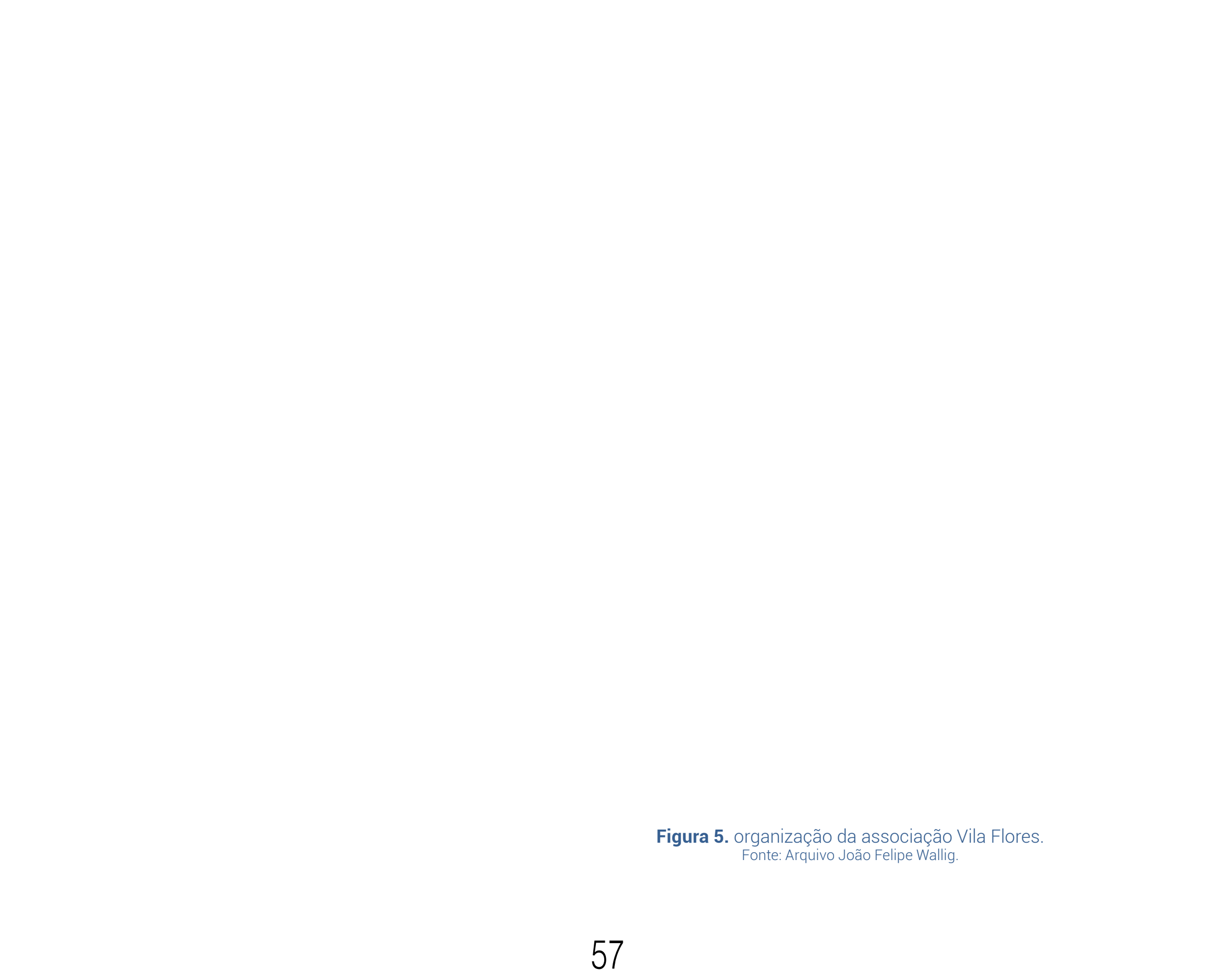


A partir do entendimento da contemporaneidade, Ascher (2010), Lipovetsky (2004), Harvey (1992) e Castells (2013) apresentam, para além de sua conceituação, questões paradigmáticas advindas das transformações sociais e históricas que a inauguram.

Para Ascher (2010), o período pós-guerra se apresenta como um cenário da hipermodernidade. Segundo o autor, os novos paradigmas que se apresentam estão diretamente relacionados ao que se entende por era cognitiva. Com origem no declínio do modelo keynesiano e nas possibilidades apresentadas pela evolução das tecnologias de informação e comunicação apresenta-se, então o que Ascher entende por Segunda Revolução Moderna. Soma-se, ao conceito de Ascher, a definição de Lipovetsky (2004) que, com foco no modo de produção nos tempos hipermodernos, conceitua a hipermodernidade como um estado cultural da pós-modernidade.

Harvey (1992), por sua vez, ao comparar a contemporaneidade com a modernidade, apresenta o conceito de flexibilidade presente na contemporaneidade em contraponto ao termo da rigidez na modernidade.

(...) se apoia na flexibilidade dos processos de trabalho, dos mercados de trabalho, dos produtos e padrões de consumo. Caracteriza-se pelo surgimento de setores de produção inteiramente novos, novas maneiras de fornecimento de serviços financeiros, novos mercados e, sobretudo, taxas altamente intensificadas de inovação comercial, tecnológica e organizacional (Harvey, 1992, p. 140).
Castells (2013) apresenta oposição entre a rede e o ser. Por um lado, a sociedade em rede - a crescente informatização e automação dos processos - e, por outro lado, o novo liberalismo mundial. A era da informação se apresenta como contrária à fragmentação social. Castells define rede como um conjunto de nós interligados. Nó é o ponto onde uma curva se entrecorta. Redes são estruturas abertas com capacidade de se ampliar de forma ilimitada, agregando novos nós - desde que esses novos nós consigam se comunicar na rede, ou seja, desde que compartilhem os mesmos códigos de comunicação.

É a partir do entendimento de uma sociedade em rede e de uma nova ordem, bem como de suas questões e desafios, é que se identificam os conceitos complementares de código-aberto e de organização sistêmica. Acredita-se que tais conceitos, identificados no estudo de caso do Vila Flores, apresentam-se como ferramentas insurgentes em resposta aos paradigmas da contemporaneidade.

O arquiteto e urbanista João Felipe Wallig (2018), em entrevista, apresenta a colocação de Gehl (2011) "Primeiro a vida, depois espaços públicos, só então edifícios - o inverso nunca funciona" como uma afirmação do processo do Vila Flores. O processo arquitetônico, fundamentado nas práticas sociais advindas das atividades do coletivo Vila Flores, mostrar-se como uma importante contribuição para a produção arquitetônica contemporânea. 
Soma-se a esta estratégia - de valorização das questões socioculturais como variáveis determinantes no processo de projeto -, a comparação estabelecida entre o processo dialógico e o processo estratégico estabelecida por Souza (2001). Conforme o autor, enquanto que um processo de planejamento ou projetação estratégico tem o foco nos fins e busca os meios para chegar a um determinado fim, o processo dialógico tem o foco nos meios e desconhece o fim, uma vez que o fim é resultante do diálogo entre diversas variáveis.

Um exemplo do processo dialógico do Vila Flores é a sua organização em quatro âmbitos, sendo eles os residentes, a arquitetura, a administração e a Associação Cultural Vila Flores. Esta organização advém da auto-observação por parte do coletivo, durante o Projeto Simultaneidades (Figura 6) ocorrido em dezembro de 2013. O projeto, que abriga entusiastas, artistas e coletivos em valorizar espaços que guardam as memórias da cidade, transformando-os em núcleos de convívio, de trocas de experiência e de simultaneidades afetivas e criativas, teve no Vila Flores a sua primeira edição.

A partir das ênfases que, de maneira orgânica se apresentaram no evento, é que se entendeu a complementaridade das quatro áreas identificadas. Os residentes e a comunidade propõem que todos os espaços acolham propostas que tenham uma ligação com quatro eixos norteadores: Arquitetura e Urbanismo, através de debates e atividades de projetos que visam a melhoria de vida da cidade; Empreendedorismo, por meio da conexão entre negócios criativos e colaborativos, por meio do incentivo aos produtores locais; Educação, sendo uma forte troca de conhecimentos e experiências com cursos encontros e oficinas; e Arte e Cultura, compreendendo música, dança, artes visuais e cênicas.

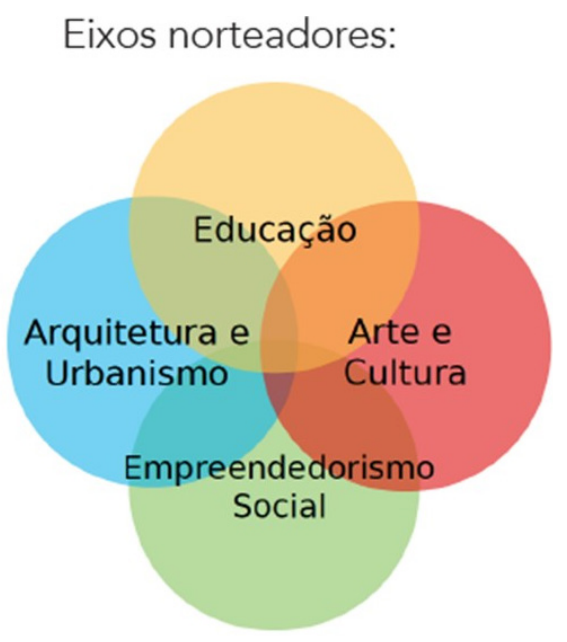

Figura 7. Eixos norteadores da estrutura organizacional do Vila Flores. Fonte: Arquivo João Felipe Wallig.

O diagrama elaborado pela Associação Cultural Vila Flores (Figura 7) ilustra a organização do coletivo a partir das quatro grandes áreas identificadas durante o Projeto Simultaneidades. A organização sistêmica, segundo Chiavenato (1993), caracteriza-se por uma visão focada no conjunto, por um pensamento sintético com maior foco em juntar que em separar as partes e o entendimento de sistema aberto. Segundo o autor, um sistema consiste em um "Conjunto de elementos interdependentes e interagentes ou um grupo de unidades combinadas que formam um todo organizado" (Chiavenato, 1993, p. 545). 
É a partir do entendimento de organização sistêmica que o Vila Flores se afırma como coletivo, diferentemente de organizações tradicionais que se caracterizam por hierarquias piramidais e clara divisão do trabalho. A organização das atividades do coletivo, bem como a abordagem colaborativa, apresenta-se no Vila Flores como uma abordagem de baixo para cima, pautada por uma visão coletiva e orgânica. Essa abordagem pode ser observada com a abertura das portas do espaço, pelos proprietários, para iniciativas que tivessem propósitos parecidos para construir coletivamente a iniciativa que, mais adiante, se tornaria o Vila Flores. O primeiro encontro ocorreu em dezembro de 2013, com a duração de três dias reunindo de acordo com Wallig e Sielski (2013), com dois grupos de pesquisa que trabalham com a prática colaborativa como possibilidade de troca de saberes e descontinuidades no cotidiano. O primeiro é o Arte e Vida nos limites da representação, da Universidade do Estado de Santa Catarina (UDESC), que reúne artistas e colaboradores do coletivo Geodésica Cultural Itinerante, e o segundo é o Transitar, da Universidade Federal de Pelotas (UFPEL).

Em conjunto com esses grupos de pesquisa dois grupos de projetos participaram Goma Oficina, de São Paulo, responsável pelo Projeto Arquitetônico que realiza intervenções urbanas na cidade por meio de projeções e video maping e, o Projeto Vizinhança, de Porto Alegre, que propõe a ocupação temporária de espaços ociosos através de projetos artístico-culturais como forma de oportunizar novas experiências, estimular encontros e trocas entre vizinhos. Durante esses três dias, com a convivência entre os grupos, foi possível "discutir as diversas possibilidades para o complexo, trocando saberes, fazeres e prazeres na prática coletiva" (Wallig e Sielski, 2013, p. 4). No último dia, o evento foi aberto à comunidade por meio de divulgação pelas redes sociais. Como interessados ao projeto que estava aberto a ser pensado em conjunto com os moradores do bairro e demais interessados, compareceram moradores, artistas do bairro, vizinhos, comércio local, amigos da associação Refloresta, curiosos, músicos, outros coletivos, grupos de teatro, fotógrafos, grafiteiros assim como arquitetos. Essa iniciativa teve como meta compartilhar e discutir a ideia de forma coletiva.

A partir dessa iniciativa, o projeto vem crescendo e ganhando novos parceiros. João Felipe Wallig e Vitor Pena (2016) relatam que a Associação Cultural Vila Flores nasceu em 2014, com pequenos empreendedores e artistas que desenvolvem atividades próprias de sua área de atuação e que, além de gerenciar o espaço coletivamente, desenvolvem projetos compartilhados que promovem a interação e diálogo entre as diferentes áreas do conhecimento.Conforme Wallig e Pena (2016) "Ocupar, trabalhar, viver e conviver são os pilares para o processo de readequação do conjunto arquitetônico." O Vila Flores é formado por três espaços comuns: Galpão, Pátio e Miolo. O Galpão Multiuso é utilizado pelos artistas e eles elaboram a programação do espaço. É o espaço voltado para exposições, apresentações, exibições, encontros e, a cada evento ou atividade, descobre novas potencialidades ou necessidades de adequação que permitem a fusão e convivência de diversas práticas e linguagens artísticas. Já o Pátio Central é considerado o coração do complexo. Por 
meio do seu uso, percebeu-se a necessidade de verde sombra, assentos, que vem sendo construidos locados coletivamente. E o Miolo exercendo a função educativa, destina-se à troca de saberes, cursos, oficinas, palestras.

Uma gestão colaborativa propõe ter os processos de decisão horizontais. De acordo com o site do Vila Flores (Vila Flores, 2018)

e tudo muito orgânico e transmutável. Às vezes, as decisões mais urgentes são de cima para baixo, em que o Imobiliário ou a Arquitetura, pensando no bem comum das pessoas e do espaço, precisam dar respostas rapidas e agem sem consultar a Associaçấo pra cima (caminho inverso), em que a Associação le vanta as pautas, vota e discute com o Imobiliário ou a Arquitetura.

O processo dialógico, conforme exposto, com ênfase nos meios, apresenta-se como uma interpretação de todos os agentes postos em diálogo. Este processo, por sua vez, mostra-se como um caminho que abre espaço para incertezas. 0 processo, neste sentido, amplia a colaboração. Nesta linha, o coletivo apresenta uma prática de código aberto. 0 código aberto, entendido como uma prática transparente e colaborativa, revela todos os processos para a comunidade interna e externa. Acredita-se, desta maneira, que globalmente se faz possível colaborar de maneira abrangente. Neste modo de operação, aberto, observa-se a pertinência de inúmeras variáveis que atuam em colaboração para uma construção coletiva, onde que se busca o maior número de possibilidades no sentido de cercar as incertezas do processo.

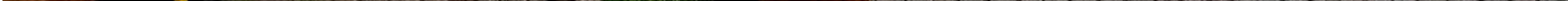




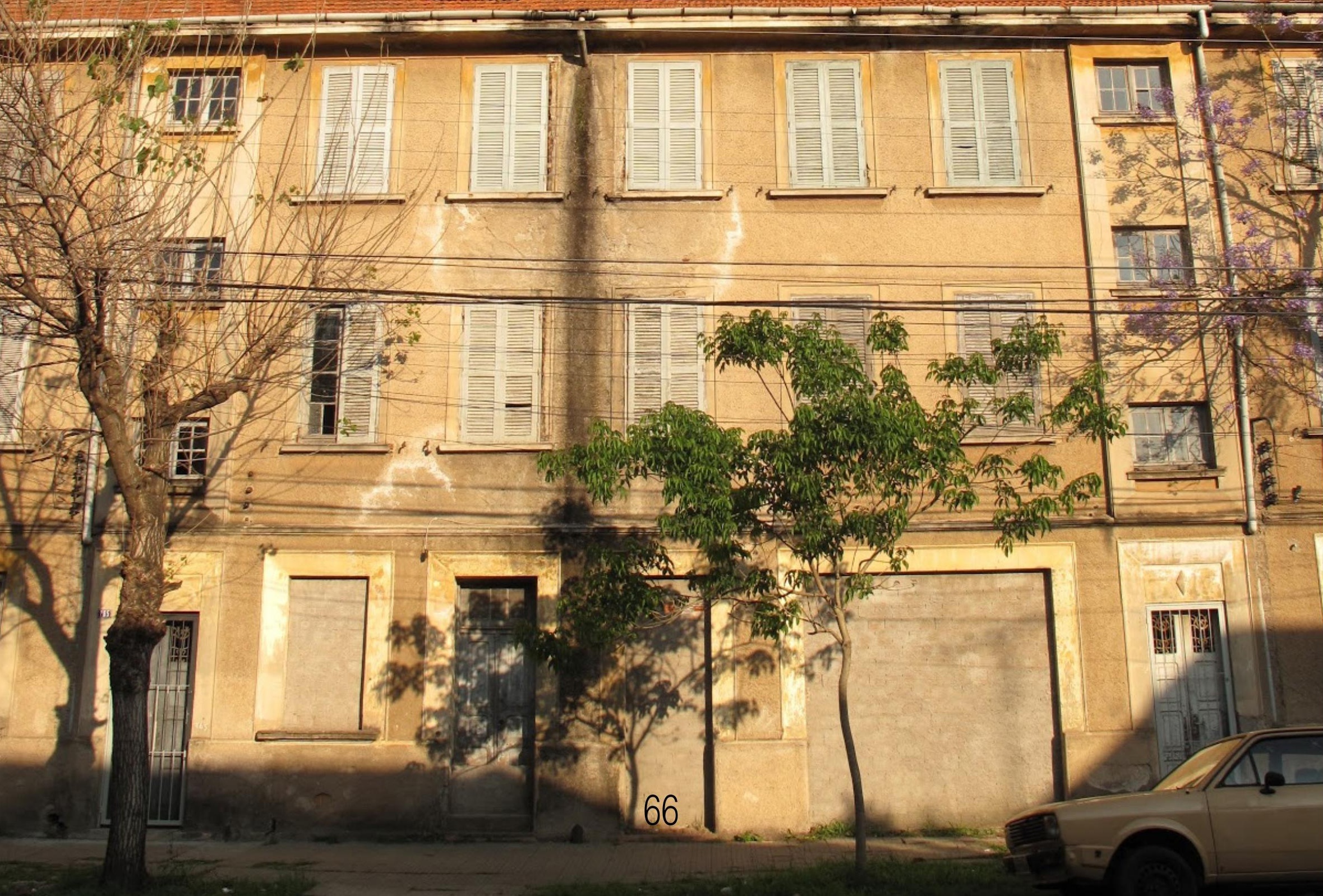


As práticas como o código aberto, a organização sistêmica e a operação de baixo para cima, identificadas a partir do estudo de caso, apresentam-se práticas diretamente relacionada aos novos paradigmas contemporâneos. A partir do exposto, entende-se que, por meio destas práticas que tem por ênfase a colaboração, a contemporaneidade apresenta-se como um novo cenário.

\section{Considerações Finais}

A economia colaborativa e as novas formas de gestão e organização estão ganhando cada vez mais enfoque no contexto contemporâneo. Com a tecnologia da informação, o advento da internet, e as mídias sociais, a formação de espaços colaborativos se intensificou e a busca por novas formas de trabaIho acompanhou essas rupturas.

O presente buscou compreender, por meio do estudo de caso do Vila Flores, as possíveis motivações para criação de espaços colaborativos e quais estratégias são desenvolvidas pela arquitetura para acompanhar esse processo. Foram analisados os meios utilizados no engajamento e na construção do sentimento de pertencimento e formação de comunidade dos atores envolvidos no projeto colaborativo Vila Flores, pelo viés de Ascher (2010), Lipovetsky (2004), Harvey (1992) e Castells (2013).

Apresenta-se, a partir do exemplo do Vila Flores, um novo modelo de processo criativo. Em contraponto à produção da era industrial, o processo de projeto contemporâneo tem raiz na colaboração. Neste sentido, a autoria se coloca em segundo plano, uma vez que o projeto é resultante de um proces- so complexo e dialógico. Neste processo, diversos atores são participantes. Talvez tal postura justifique a autoria pertencer a uma equipe. É nesse cenário de coletivos, em contraponto ao cenário de autores, que se identifica a prática de criação dialógica. No contexto aqui discutido, o usuário é parte do projeto, e o projeto se modifica para se adequar às novas transformações socioculturais que surgem no decorrer do uso da edificação. Conclui-se que, para bem projetar a cidade contemporânea, precisamos desafiar suposições impensadas sobre a vida urbana. Faz-se necessário adotar ideias sobre viver "juntos", convivência e estímulos de diferenças, tanto visuais quanto sociais.

\section{REFERÊNCIAS}

Archdaily Brasil. (24 Mai, 2016). Vila Flores / Goma Oficina. Disponível em https://www.archdaily. com.br/br/788135/vila-flores-goma-oficina

Ascher, F. (2010). Novos princípios do urbanismo. São Paulo: Romano Guerra.

Castells, M. (2013). Redes de Indignação e Esperança: movimentos sociais na era da internet. ( $1^{\mathrm{a}}$ Ed.) Rio de Janeiro: Zahar.

Chiavenato, I. (1993). Introdução à Teoria Geral da Administração. São Paulo: Makron.

Gehl, J. (2011). Life between buildings: using public spaces. Copenhagen: Danish Architecture Press.

Lipovetsky, G. (2004). Os tempos hipermodernos. São Paulo: Barcarolla.

Harvey, D. (1992). Condição pós-moderna. São Paulo: Edições Loyola, 
Sennett, R. (2012). Juntos. Os rituais, os prazeres e a política da cooperação. Rio de Janeiro: Record.

Fundação Bienal de São Paulo. (2018). Mostra 'juntos' representa o Brasil na Bienal de Veneza 2016. Disponível em http://www.bienal.org.br/post/2401

Souza, M. (2001). Mudar a cidade: uma introdução crítica ao planejamento e à gestão urbanos. Rio de Janeiro: Bertrand Brasil.

Vila Flores. (2018). Vila Flores. Disponível em https:// vilaflores.wordpress.com/about/

Wallig, J. e Pena, V. (2016). Vila Flores. Um processo arquitetônico: ressignificação, coletividade e aprendizado. Porto Alegre, 2012-2016. Vitruvius, 16(184.01). Disponível em <http:// www.vitruvius.com.br/revistas/read/projetos/16.184/6015

Wallig, A. e Sielski, L. (2013). Projeto Vila Flores: práticas artísticas colaborativas pela revitalização de processos criativos no meio urbano. In: Anais... 22 ${ }^{\circ}$ Encontro da Associação Nacional de Pesquisadores em Artes Plásticas, (3012-3025). Belém, Brasil.

Wallig, J. (Ago 24, 2018). Entrevista concedida às autoras. Porto Alegre.
Roberta Krahe Edelweiss es graduada en Arquitectura y Urbanismo del Centro Universitário Ritter dos Reis - UNIRITTER (2000) y Doctora en Proyectos Arquitectonicos por la Escola Técnica Superior de Arquitetura de Barcelona - Universidade Politécnica da Catalunha - ETSAB/UPC (2008). Actualmente trabaja en Universidade do Vale do Rio dos Sinos UNISINOS, donde es coordinadora del Master Profesional en Arquitectura y Urbanismo, Editora en Jefe de Arquiteturarevista y miembro del Núcleo Docente Estructurante del Curso de Arquitectura y Urbanismo. Igualmente, es Directora del Instituto dos Arquitetos do Brasil - Departamento do Rio Grande do Sul (IAB RS) y también coordina la Editorial de la revista Espaço IAB RS. Opera en las áreas de Proyecto de Arquitectura y Urbanismo, Tecnología y Desarrollo Sostenible. 